\title{
Light Pipe Comparative Measurement
}

\begin{abstract}
The illuminance measurement method for a comparative evaluation of two light pipes is described in the paper. Two commercially available light pipes of similar dimensions were evaluated for light transmittance. Measurement and data processing methodology was completed for the comparison of the light pipe efficiency. Results of continual one minute intervals measurements are presented for three month monitoring.
\end{abstract}

Keywords: light pipes, daylighting, illuminance measurement.

\section{Introduction}

Light pipes are available for daylighting of windowless internal rooms. They can transmit light due to multireflections on the pipe internal reflective surface $[1,2]$. In common cases the light pipes are connected with a roof structure and ceiling of the lower floor to transmit daylight from exterior through one floor distance to indoors [3]

Light pipes have been topics of many theoretical and/or experimental evaluations [4-6] and comprehensive technical documents $[8,9]$. Light efficiency of these systems depends on their dimensions, as diameter and length and on interna reflectance of the pipe as well as on optical properties of the transparent roof and ceiling covers [8]. The location of the light pipes in building and its connection with constructions plays also key role for daylight transmittance [9].

\section{Studied light pipes}

Two commercially available light pipes of similar dimensions were evaluated for light transmittance. The light pipes were installed into a steel load bearing construction located on the testing box, Fig. 1. The box of floor dimensions $5.80 \mathrm{~m} \times 2.30 \mathrm{~m}$ and clearance height $2.2 \mathrm{~m}$ was divided into two identical cells illuminated through the tested light pipes, Fig. 2.

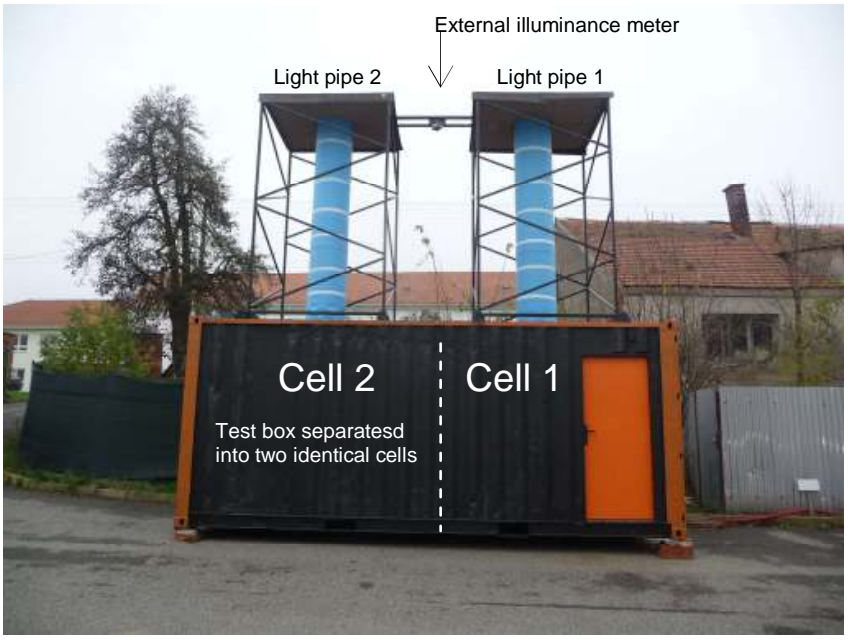

Fig.1. Photograph of the test box with two light pipes installation

Daylight level from light pipes of length $2.5 \mathrm{~m}$ and diameters $0.53 \mathrm{~m}$ (Cell 1) and $0.55 \mathrm{~m}$ (Cell 2) were studied. Both of the light pipes have acrylate domes on the top and transparent diffuser connected with the test box ceiling Illuminance measurement was carried out due to a set of illuminance meter sensors - five internal sensors in every cell (Fig. 2, Fig.3) and one extenal sensor (Fig. 1, Fig. 2) that is protected by plastic transparent cover.
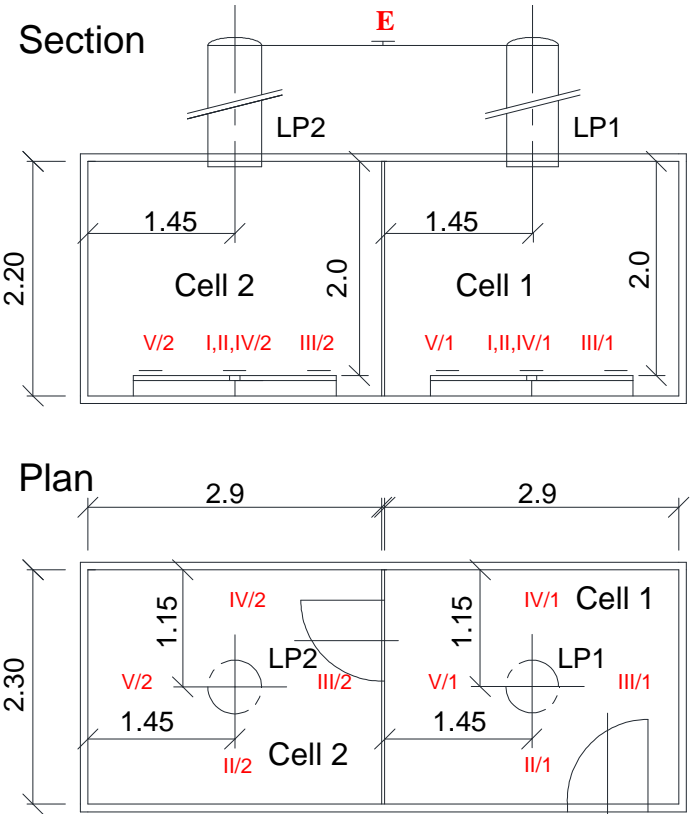

Fig.2. Dimension of the text box separated into two cells LP1 - Light pipe for Cell 1 (diameter $0.53 \mathrm{~m}$, length $2.5 \mathrm{~m}$ ) LP2 - Light pipe for Cell 2 (diameter $0.55 \mathrm{~m}$, length $2.5 \mathrm{~m}$ ) $\mathrm{E}-$ external sensor for exterior horizontal illuminance measuremet $\mathrm{V} / 1-\mathrm{V} / 1$ - internal illuminance meters in Cell 1

$\mathrm{I} / 2$ - V/2 - internal illuminance meters in Cell 2

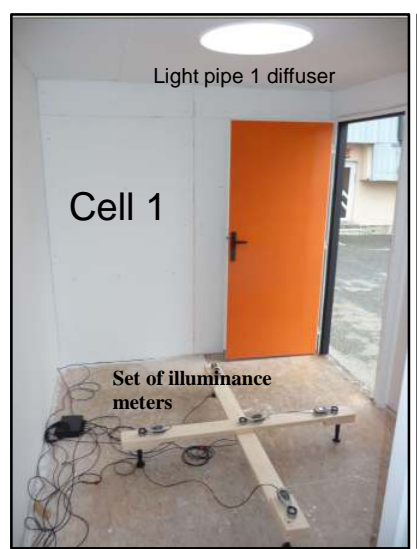

a)

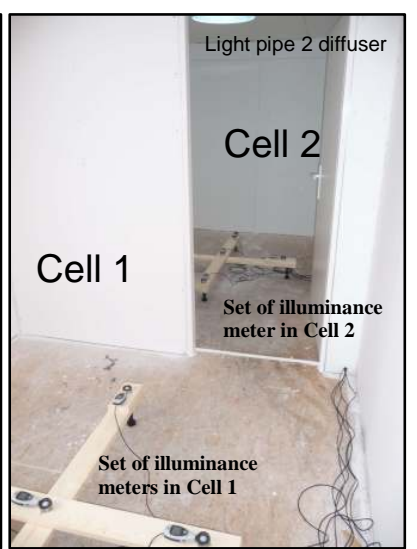

b)
Fig.3 Photographs of illuminance meters installations in the cells a) Cell 1 connected with the entrance door

b) Cell 1 and Cell 2 separated by internal partition with door

The couple of five illuminance meters set were fixed on wooden profiles located in position $20 \mathrm{~cm}$ over the test box floor level; installed in cells of the box. The every illuminance set consists of illuminance meters in the position of the light pipe vertical axis (vertical distance between the central illuminance sensor and the light pipe 
diffuser is $2 \mathrm{~m}$ ) and four illuminance metres located in four positions at distance $1 \mathrm{~m}$ from the central axis, Fig. 2, Fig. 3 and Fig. 4.

\section{Illuminance measurement}

Illuminance meters DT-86 were used for the light measurements. Maximal range of measurement is $40 \mathrm{klx}$, accuracy $0.1 \mathrm{~lx}$, with automatic range switching. An electronic data collecting system was completed for the illuminance data processing.

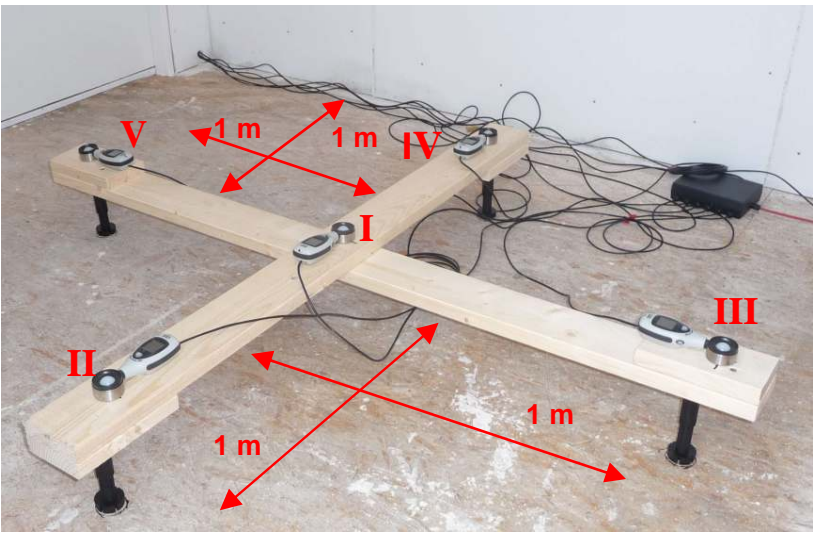

Fig.4. Photograph of the luminance meters set installation

I, II, III, IV and V - illuminance meter sensors

The electronic device uses measured data from illuminance meter displays and it sends them to a computer data processing. The selected illuminance meters uses multiplex seven segment and four digit LCD displays. Decimal point and unit $L x$ are displayed in addition to 4 digits as well as fc (foot-candle), MAX, 10x, 100x and battery symbols.

Measurement data sorting is completed due to busbar RS485 connected with illuminance meters and the computer. The busbar is standardized with specification of TIA-485-A

The busbar can use 32 connections for distances up to $1200 \mathrm{~m}$ and transmission speed $100 \mathrm{~kb} / \mathrm{s}$ or $35 \mathrm{Mb} / \mathrm{s}$ per 10 $\mathrm{m}$. Ends of the transmission cables should have resistors of 120 Ohms for resistance against transmission signal reflection at the ends (impedance matching).

The transmission speed of $4.8 \mathrm{~kb} / \mathrm{s}$ was used for the light pipe illuminance measurement application. The impedance matching for speed $4.8 \mathrm{~kb} / \mathrm{s}$ is negligible for 10 $\mathrm{m}$ long connecting cables (it can be important for the cable length about $50 \mathrm{~km}$ ). For this reason the ending resistors of $120 \mathrm{Ohms}$ were excluded form the apparatus.

The star network was applicated for the connection due to four wire cable where 12 wires are for power supply (from $9 \mathrm{~V}$ adapter) and two ones for the data transmission. In total eleven illuminance meters $(2 \times 5$ internal sensors and 1 external sensor) with electronic circuit are connected with the star network. The electronic device circuit has one-chip microcontroller ATmega168 for the transmitted signal decoding.

The illuminance meter display data reading is for three times from the display segments. In case of three comparable readings the data digit is selected and recorded. The recording time is about $20 \mathrm{~ms}$. In case that the above mentioned process is not successful the procedure is repeated up to four times. In total the process duration can be prolonged from $20 \mathrm{~ms}$ to $100 \mathrm{~ms}$.

The measured data sorting software was completed in system LabVIEW for MS Windows and it is applicable for PC or notebooks. The measurement set is connected with the computer via connector USB/RS485. The operational system gives specification to the connector and this specification is written into the measurement procedure program. This program operates in the computer in the following way:

- it gives order to all electronic circuits for measurement data monitoring on the illuminance meter display.

- particular illuminance meters are ordered for the measured data records,

- data transmission from all illuminance meters are recorded nearly simultaneously (time delay of individual readings is less than $1 \mathrm{~s}$, usually less than $0.4 \mathrm{~s}$ ),

- in case of measurement errors the program orders the particular illuminance meter for the corrected value,

- the measurement program sends order to illuminance meters to restart in every five minute intervals (the restart time is 5 seconds).

- time interval of data collecting is between 1 and 5 minutes.

The program also controls display of measured values on the PC monitor. Illuminance data are displayed into columns as data monitored on particular illuminance meters. Two columns belongs to every individual illuminance meter measurement - the first column contains values of illuminance in lux, in the second one notes are included (measurement units - lux or fc, error and overloading). The measured data are recorded into the text file that can be used for the MS Excel data processing.

\section{Results}

The mentioned daily illuminance measurements have been monitored in one minute intervals since February 2015. A summary of monitored data for three month period is presented in the paper. The measurements were carried out for illuminance sensors $\mathrm{I} / 1$ to $\mathrm{V} / 1$ in Cell 1 and $\mathrm{I} / 2$ to $\mathrm{V} / 2$ in Cell 2 (Fig. 2 and Fig. 4) located on wooden profile in the vertical distance $2 \mathrm{~m}$ from the light pipes diffuser.

Examples of results of the illuminance measurements are presented in Fig. 5 and Fig. 6. Daily illuminance measurements of day 19/02/2015 for conditions of nearly overcast sky with daily average external illuminance 27157 lux and median value 18032 lux give results about daylight efficiency of the studied light pipes, Fig 5a). Another day of the measurements on $05 / 04 / 2015$ is characterized for dynamic changes of illuminance with daily average external illuminance 34135 lux and median value 31068 lux, Fig. $5 b)$.

It is obvious from the graphs that the light pipe 1 (LP1) installed for Cell 1 has higher efficiency compared to the LP2 of Cell 2. This finding can be also controlled in details in graph for one hour data monitoring under overcast sky conditions during time interval between 12:00 and 13:00 on 02/03/2015, for hourly average external illuminance 11722 lux and median value 10041 lux.

\section{Conclusion}

Illuminance measurements were completed for two commercial light pipes of comparable dimensions. The measurements were focused on daylight efficiency of the two light guiding systems. Graphs of Fig. 5 and Fig. 6 show that both of the light pipes have similar distribution of internal illuminance in the test box cells. Despite of smaller diameter of $0.53 \mathrm{~m}$ the light pipe installed in Cell 1 gives higher illuminance compared to light intensity under the light pipe of diameter $0.55 \mathrm{~m}$ located in Cell 2. Better daylight transmittance is because of highly reflective internal surface of the light pipe of Cell 1.

Mirrored internal surface gives possibility for high light efficiency of the light pipe. Differences of internal illuminance measurements in Cell 1 and Cell 2 are visible fromgraphs. Internal illuminance levels monitored for LP1 
and LP2 vary from about 30 to 110 lux for overcast and intermediate sky conditions with average external horizontal illuminance up to 28000 lux. The differences in internal illuminance measurements are even higher - up to about 500 lux in case of sky conditions with dynamic changes of partly cloudy or clear sky, Fig. 5b). The light measurements will continue for specification of the total annual illuminance profile under clear and intermediate and overcast sky conditions.
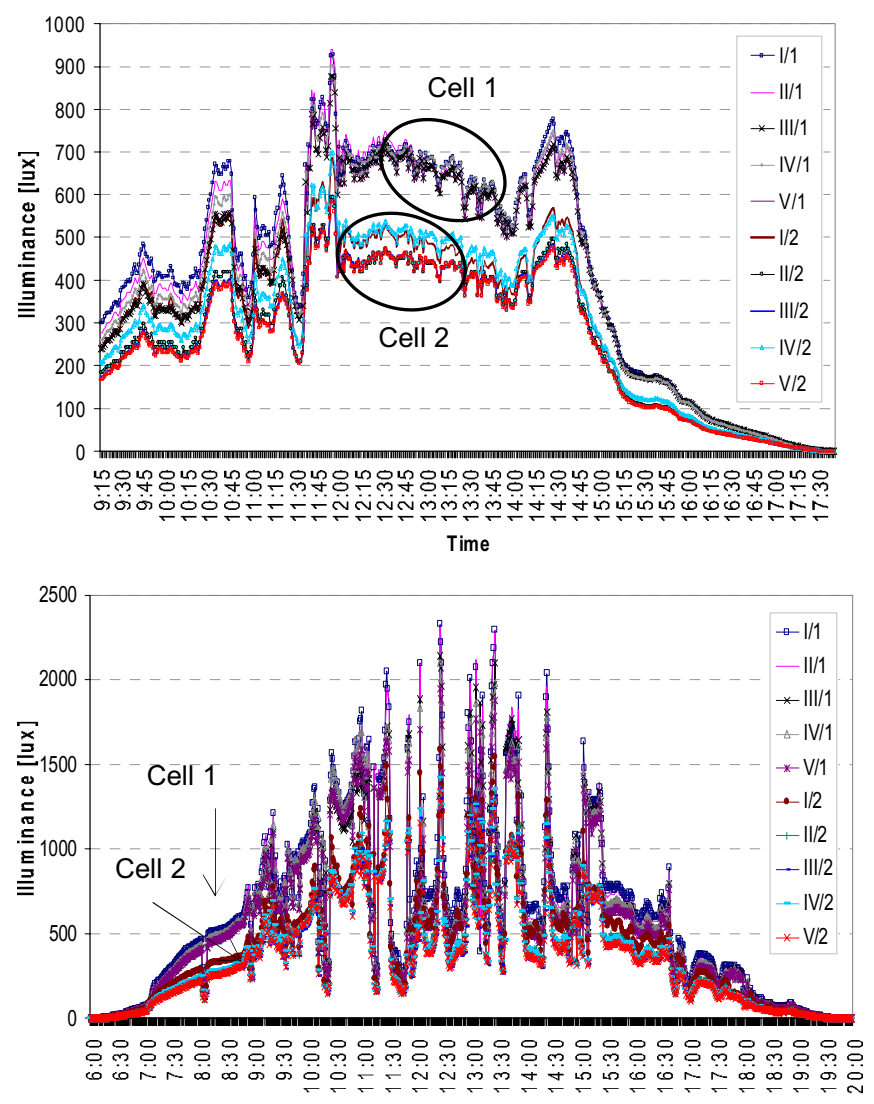

Time

Fig. 5 Daily illuminance measurement,

a) day 19/02/2015, nearly overcast sky, average external illuminance 27157 lux, median value 18032 lux

b) day $05 / 04 / 2015$, dynamic changes of external illuminance, average external illuminance 34135 lux, median value 31068 lux.

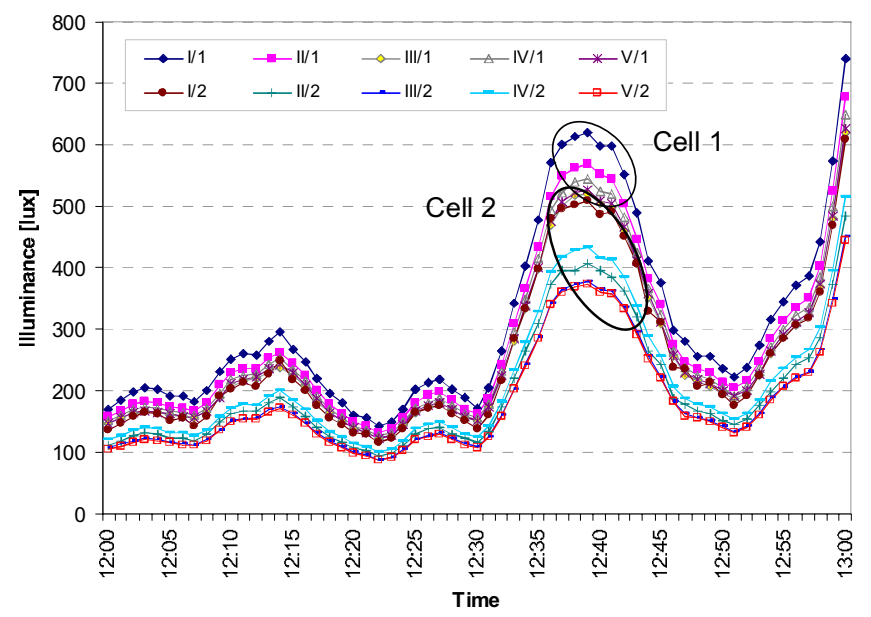

Fig. 6 Hourly illuminance measurement (12:00-13:00), overcast sky, day 02/03/2015, hourly average external illuminance 11722 lux, median value 10041 lux

\section{Acknowledgement}

This paper has been worked out under the project no. L01408 "AdMaS UP - Advanced Materials, Structures and Technologies", supported by Ministry of Education, Youth and Sports under the "National Sustainability Programme I" and under the project TE02000077, Smart Regions-Buildings and Settlements Information Modelling, Technology and Infrastructure for Sustainable Development.

\section{References}

[1] Carter, D., LRT Digest 2 Tubular daylight guidance systems. Lighting Research and Technology, 46 (2014), No. 4, 369-387.

[2] Rosemann, A., Kaase, H., Lightpipe applications for daylighting systems. Solar Energy, 78, (2005), No. 6, 772-780.

[3] Shao, L., Riffat, S.B., Daylighting using light pipes and its integration with solar heating and natural ventilation. Lighting Research and Technology, 32 (2000), No. 3, 199-139.

[4] Carter, D.J., The measured and predicted performance of passive solar light pipe systems. Lighting Research and Technology, 33,(2002), No. 1, 39-52.

[5] Jenkins, D., Muneer, T., Modelling light pipe performances - a natural daylighting solution. Building and Environment, 38, (2005), No. 7, 965-972.

[6] Kocifaj, M., Darula, S., Kittler, R., HOLIGILM: hollow light guide interior illumination method - an analytic calculation approach for cylindrical light-tubes. Solar Energy, 82, (2008), No. 3, 247-259

[7] Kocifaj, M., Kundracik, F., Darula, S., Kittler, R., Availability of luminous flux below a bended light-pipe: design modelling under optimal daylight conditions. Solar Energy, 86, (2012), No. 9, 2753-2761.

[8] CIE 164:2005. Hollow light guide technology and applications. CIE Technical Report, Vienna 2005.

[9] CIE 173:2006. Tubular daylight guidance systems. CIE Technical Report, Vienna 2006.

\section{Authors: \\ doc. ing. Jiř PIch, CSc., Czech Lighting Society - ČSO, Czech Republic,e-mail: iiri plch@volny.cz}

prof. Ing. Jitka Mohelíková, Ph.D., Brno University of Technology, Czech Republic, e-mail: mohelnikova.j@fce.vutbr.cz

Ing. Jakub Král, TOPWET,s.r.o.Ostrovačice, Czech Republic, email: jakub.kral@topwet.cz 